Int. J. Electrochem. Sci., 16 (2021) Article ID: 21085

International Journal of

ELECTROCHEMICAL

SCIENCE

www.electrochemsci.org

\title{
Corrosion of Dental Alloys Used for Mini Implants in Simulated Oral Environment
}

\author{
Helena Otmacic Curkovic ${ }^{1}$, Marina Ivanko ${ }^{1}$, Darko Pop Acev ${ }^{2}$, Ervin Kamenar $^{3,4}$, \\ Ivana Jelovica Badovinac ${ }^{3,5}$, Stjepan Spalj ${ }^{6,7, *}$ \\ ${ }^{1}$ University of Zagreb, Faculty of Chemical Engineering and Technology, Department of \\ Electrochemistry, Savska 16, 10000 Zagreb, Croatia \\ ${ }^{2}$ Private practice Pop Acev Skopje, 1000 Skopje, North Macedonia \\ ${ }^{3}$ University of Rijeka, Centre for Micro- and Nanosciences and Technologies, Radmile Matejcic 2, \\ 51000 Rijeka, Croatia \\ ${ }^{4}$ University of Rijeka, Faculty of Engineering, Laboratory for Precision Engineering, Vukovarska 58, \\ Rijeka 51000, Croatia \\ ${ }^{5}$ University of Rijeka, Department of Physics, Radmile Matejcic 2, 51000 Rijeka, Croatia \\ ${ }^{6}$ University of Rijeka, Faculty of Dental Medicine, Department of Orthodontics, Kresimirova 40, \\ 51000 Rijeka, Croatia \\ ${ }^{7}$ J. J. Strossmayer University of Osijek, Faculty of Dental Medicine and Health, Department of Dental \\ Medicine, Crkvena 21, 31000 Osijek, Croatia \\ "E-mail: stjepan.spalj@fdmri.uniri.hr
}

doi: 10.20964/2021.08.15

Received: 28 March 2021 / Accepted: 24 May 2021 / Published: 30 June 2021

The aim of this study was to explore the resistance to general and pitting corrosion of stainless steel and titanium-based orthodontic mini implants in an oral environment. Studies were performed in artificial saliva and in the presence of two oral hygiene products (one containing chlorhexidine digluconate with sodium fluoride and another containing probiotic bacteria) that are usually recommended to orthodontic patients. The results showed that mini implants made from stainless steel have lower resistance to corrosion than titanium implants. General corrosion was increased in both steel and titanium implants when antiseptic agents containing fluoride ions were used, while the tendency towards pitting corrosion was not noticeably altered. Probiotics, on the other hand, had a beneficial effect on general corrosion resistance but were associated with an increased tendency towards pitting corrosion for both implant materials.

Keywords: mini implants, corrosion, antiseptic, probiotic, artificial saliva

\section{FULL TEXT}


(C) 2021 The Authors. Published by ESG (www.electrochemsci.org). This article is an open access article distributed under the terms and conditions of the Creative Commons Attribution license (http://creativecommons.org/licenses/by/4.0/). 